\title{
A DIMENSÃO LÚDICA E AS PRÁTICAS PEDAGÓGICAS PARTICIPATIVAS DAS CRIANÇAS NA AMAZÔNIA AMAPAENSE
}

\author{
Ângela do Céu Ubaiara Brito' \\ Adriana Machado de Souza²
}

\section{RESUMO}

A pesquisa investiga em que medida a dimensão lúdica está vinculada com práticas pedagógicas participativas das crianças na Amazônia amapaense? Objetivou-se compreender a relação da ludicidade e as práticas pedagógicas que reconhecem e valorizam a criança como sujeito participante e construtor de seu conhecimento. A metodologia utilizada se fundamentou na abordagem qualitativa, ancorada no método Estudo de Caso, tendo como principais técnicas e instrumentos de coleta de dados: a entrevista semiestruturada e o grupo focal com as professoras; as rodas de conversa com as crianças e a observação participante nos contextos de cada professora com suas crianças. O locus de pesquisa foi uma EMEl localizada em área urbana periférica do Município de Macapá/AP. UtilizoU-se no tratamento dos dados, os princípios presentes na Hermenêutica-Dialética. Os resultados demonstram que o lugar ocupado pela dimensão lúdica encontra-se claramente definido nos documentos oficiais e no discurso pedagógico, mas mantem-se incompreendido e inferiorizado no contexto educacional, muito devido à burocratização e pedagogização docente e das exigências sociais que enaltecem práticas transmissivas e desqualificam práticas fundadas na participação e no reconhecimento da criança amazônica como sujeito histórico e cultural, pois estas não representam a lógica da sociedade capitalista.

Palavras-chave: Educação Infantil. Ludicidade. Práticas Pedagógicas.

\footnotetext{
1 Doutora em Educação pela Universidade de São Paulo - USP (2013), Mestre em Direito Ambiental e Políticas Públicas pela Universidade Federal do Amapá - UNIFAP (2008) e graduada em Licenciatura Plena em Pedagogia pela Universidade Federal do AmapáUNIFAP (1999). Líder do Grupo de Pesquisa Ludicidade, inclusão e Saúde (LIS). Membro do Grupo de Pesquisa Contextos Integrados de Educação Infantil, da Faculdade de Educação da USP (FEUSP). Prof ${ }^{a}$. Adjunta da Universidade do Estado do Amapá (UEAP) e do Programa de Mestrado em Educação (PPGED) da Universidade Federal do Amapá (UNIFAP). Orcid iD: ORCID id: https://orcid.org/0000-0001-8301-2653. E-mail angela.brito@vepa.edu.br

2 Licenciada em Pedagogia pela Universidade Federal do Amapá - UNIFAP (1998), Especialista em Docência no ensino superior pelo Instituto Brasileiro de Pós-Graduação e Extensão - IBPEX (2004), Especialista em Tecnologias da Educação - PUC-Rio (2010), Mestra em Educação pela Universidade Federal do Amapá - UNIFAP. Professora efetiva do Quadro Funcional do Estado do Amapá. Orcid iD: https://orcid.org/0000-0002-4335-8163. E-mail: adri.m.souza.75@bol.com.br
} 


\title{
THE PLAYFUL DIMENSION AND THE PARTICIPATORY PEDAGOGICAL PRACTICES OF CHILDREN IN THE AMAPAENSE AMAZON
}

\begin{abstract}
Does the research investigate the extent to which the playful dimension is linked to the participatory pedagogical practices of children in the Amapá Amazon? The objective was to understand the relationship between playfulness and pedagogical practices that recognize and value children as participants and builders of their knowledge. The methodology used was based on the qualitative approach, anchored in the Case Study method, having as main techniques and data collection instruments: the semi-structured interview and the focus group with the teachers; conversation circles with children and participant observation in the contexts of each teacher with their children. The research locus was an EMEl located in an urban peripheral area of the Municipality of Macapá/AP. In the treatment of the data, the principles present in Hermeneutics-Dialectics were used. The results show that the place occupied by the playful dimension is clearly defined in the official documents and in the pedagogical discourse, but remains misunderstood and inferior in the educational context, largely because of the bureaucratization and pedagogization of teachers and the social demands that enhance transmissive practices and disqualify practices based on participation and recognition of the Amazonian child as a historical and cultural subject, as these do not represent the logic of capitalist
\end{abstract}

Keywords: Early Childhood Education. Playfulness. Pedagogical Practices.

\section{LA DIMENSIÓN LÚDICA Y LAS PRÁCTICAS PEDAGÓGICAS PARTICIPATIVAS DE LOS NIÑOS EN LA AMAZONÍA AMAPAENSE}

\section{RESUMEN}

La investigación investiga hasta qué punto la dimensión lúdica está vinculada con las prácticas pedagógicas participativas de los niños en la Amazonía amapaiana? Este estudio tuvo como objetivo comprender la relación de ludicidad y prácticas pedagógicas que reconocen y valoran al niño como participante y constructor de su conocimiento. La metodología utilizada se basó en el enfoque cualitativo, anclado en el método de Estudio de Caso, teniendo como principales técnicas e instrumentos para la recolección de datos: la entrevista semiestructurada y el grupo focal con los profesores; las ruedas de conversación con los niños y la observación participante en los contextos de cada maestro con sus hijos. El "locus" de investigación fue un EMEl ubicado en un área urbana periférica del municipio de Macapá/AP. Los principios presentes en hermenéutica-dialéctica fueron utilizados en el procesamiento de datos. Los resultados muestran que el lugar que ocupa la dimensión lúdica está claramente definido en los documentos oficiales y en el discurso pedagógico, pero permanecen incomprendidos e inferiorizados en el contexto educativo, en gran parte debido a la burocratización y pedagogización de los docentes y las demandas sociales que alaban las prácticas transmisivas y descalifican las prácticas basadas en la participación y el reconocimiento del niño 
amazónico como sujeto histórico y cultural, porque estos no representan la lógica de la sociedad capitalista.

Palabras clave: Educación Infantil. Ludicidad. Prácticas Pedagógicas.

\section{INTRODUÇÃO}

A ludicidade no contexto escolar é colocada como contraponto à seriedade, por isso, constantemente sua presença ou ausência é alvo de questionamentos. "A dimensão lúdica e as práticas pedagógicas participativas das crianças na Amazônia amapaense", título da pesquisa, possibilita reflexões em torno da ludicidade na Educação Infantil a partir do ponto de vista das crianças e de suas professoras, dando visibilidade aos principais sujeitos desse processo.

A ludicidade, é concebida neste estudo como um fenômeno que ocorre no íntimo de cada pessoa trazendo a sensação de plenitude e satisfação advinda de uma situação ou atividade, apresenta profunda relação com as experiências vividas (LUCKESI, 2018), mas também com estruturas simbólicas preexistentes ligadas a cultura na qual o sujeito está inserido, principalmente a criança amazônica que vive em contexto tão peculiar (BROUGÈRE, 2002). Santos e Cruz (2007, p.12) corroboram afirmando que "a ludicidade é uma necessidade do ser humano em qualquer idade e não pode ser vista apenas como diversão". Assim, a pesquisa buscou investigar em que medida a dimensão lúdica está vinculada com práticas pedagógicas participativas das crianças na Amazônia amapaense? Teve como objetivo central compreender a relação da ludicidade e as práticas pedagógicas na educação infantil, no sentido de reconhecer e valorizar a criança amazônica como sujeito participante e construtor de seu conhecimento.

Os procedimentos metodológicos fundamentaram-se na abordagem qualitativa no uso do método de Estudo de Caso (YIN, 2015). Os sujeitos da pesquisa foram as crianças e as professoras de uma Escola Municipal de Educação Infantil (EMEI) da rede pública de ensino. 
A investigação tem a intenção de que os dados obtidos e as análises desses, sirvam como referência para outras pesquisas voltadas para a educação da infância e com a infância na Amazônia. E que a dimensão lúdica seja compreendida como fator indispensável quando se concebe a criança como sujeito participativo de seu processo de conhecimento ao promover um ensino pautado em aprendizagens significativas, que criam pontes afetivas entre saberes e ambiente escolar mais humanizado que harmonize razão e sensibilidade no processo educativo para e com a criança no contexto da Amazônia Amapaense.

\section{CONCEPÇÕES DE PROPOSTAS EDUCACIONAIS NA EDUCAÇÃO INFANTIL}

As aspirações sociais através da incorporação de processos educativos, que foram gradualmente sendo sistematizados, permitem traçar um percurso histórico sobre as concepções de educação destinada para a infância. Longe de representarem a totalidade dessa trajetória, os recortes apresentados, visam apenas uma percepção ampla dessas concepções. Nas sociedades primitivas, de acordo com Ponce (2013), a educação das crianças ocorria de forma espontânea e integral, apoiada na força da tradição, da ação e do exemplo. Este tipo de educação passou a ser inadequada quando houve o princípio da sociedade de classes. A mudança estrutural refletiu em divisão do trabalho e, como uma de suas consequências, a educação para a infância começou a apresentar contornos de sistematização e elitização.

As concepções geradas no senso comum ou em teorias, nem sempre científicas, também provocaram mudanças relacionadas às novas concepções que interfiram nos aspectos relacionados à educação sistematizada para as crianças. Vários foram os teóricos que contribuíram neste sentido, entre eles, Comenius, Rousseau, Pestalozzi e Froebel que ganham destaque neste estudo por terem influenciado diretamente concepções educacionais voltadas à primeira infância.

Comenius (2001, p.127) partia do princípio de que a educação escolar deveria ensinar tudo para todos. Defendia "que devem ser enviados às 
escolas não apenas os filhos dos ricos ou dos cidadãos principais, mas todos por igual, nobres e plebeus, ricos e pobres, rapazes e raparigas, em todas as cidades, aldeias e casais isolados". Advertia, ainda que a formação do ser humano ocorria com maior facilidade durante os primeiros anos de vida sendo esta a idade ideal para imprimir, o que definia como, uma boa educação, pois tanto o cérebro, como as mãos e os demais membros estariam mais flexíveis para receber informações e executar tarefas.

Rousseav, embora tendo aspectos em comum a Comenius, como o papel da mãe (educadora natural da criança), o combate ao dogmatismo da pedagogia jesuítica e uma educação próxima à natureza, distanciava-se especialmente por não carregar suas obras de conceitos religiosos. Em relação a concepção de educação para a infância, combatia o autoritarismo e o preconceito. "Rousseau revolucionou a educação de seu tempo ao afirmar que a infância não era apenas uma via de acesso, um período de preparação para a vida adulta, mas tinha valor em si mesma" (OLIVEIRA, Z., 2011, p. 65). Defendia a ideia de que a aprendizagem ocorria por meio da experiência, em atividades práticas, através da observação e da livre movimentação. Era contra todo tipo de artificialismo, adestramento e convenções sociais.

Inspirado na utopia de Rousseau, Pestalozzi buscou criar um método educacional (AMORIM, 2018). Mas ter Rousseau como referência, trouxe-lhe conflitos internos. A superação deste paradoxo consistia em reunir o que Rousseau separou: a liberdade e a obrigação; o desejo natural e as leis. Essa aproximação entre esses pólos seria possível através da ação educativa. Propunha um método que considerava a observação da natureza infantil como princípio para serem criados meios favoráveis ao desenvolvimento, colocando sempre no centro a capacidade de ação da criança, mantendo articulação constante entre três elementos essenciais: o coração, a cabeça e a mão. No Brasil, as ideias de Pestalozzi foram introduzidas através do livro "Primeiras lições de coisas", uma tradução e adaptação feita por Rui Barbosa no ano de 1880 de uma obra norte americana, com formato de manual a ser utilizado na formação de professores, disseminando 
a corrente pedagógica tradicional conhecida como pedagogia intuitiva (GASPARIN, 2010).

As ideias sobre a importância da intuição, de acordo com Kishimoto (2002), foram assimiladas por Froebel quando estagiou no Instituto de Iverdon, de Pestalozzi. Froebel acreditava que a educação destinada à infância deveria ser apenas protetora, guardadora e não prescritiva e muito menos interferidora, permitindo que a criança vivesse de acordo com sua natureza, deixando-a livre para que pudesse usar toda sua potencialidade.

O simbolismo da natureza como reveladora da vida e da unidade do desenvolvimento transforma-o em poeta da natureza. [...] Dessa simbiose com a natureza surge sua instituição infantil que recebe o nome de Kindergarden, com sentido metafórico de jardim de crianças (KISHIMOTO, 2002, p. 60).

Assim, em 1837 Froebel criou o primeiro Jardim de Infância, destinado a preparar crianças pequenas para as etapas subsequentes. Seguindo uma tendência europeia e norte-americana, os Jardins de Infância chegaram ao Brasil na década de 1870, tendo suas primeiras representações no setor privado. Oficialmente, foi incorporado ao Decreto $n^{\circ} 7.247$ de 19 de abril de 1879 (Reforma Leôncio de Carvalho). A incorporação da criação dos Jardins de Infância, no texto da lei, trouxe uma nova concepção de educação para a primeira infância, por agregarem caráter pedagógico, se diferenciavam das creches que apresentavam caráter assistencialista destinadas apenas aos filhos de mulheres que trabalhavam fora. "Os jardins de infância froebelianos penetravam nas instituições particulares, como inovação pedagógica, destinada à elite da época, como forma de mostrar a modernidade da escola" (KISHIMOTO, 1997, p. 30). A educação ofertada à infância no Brasil passou a ser reconhecida como um direito para poucos, criando uma separação nas instituições que atendiam a esse público.

A partir da LDB n. 9.394 de 20 de dezembro de 1996 (BRASIL, 1996), que reafirmou o direito à educação disposto na Constituição Federal (1988) e estabeleceu como finalidade o desenvolvimento integral da criança, o papel da Educação Infantil passou a ser cuidar e educar de forma 
integrada, tendo a participação como um dos eixos norteadores à prática pedagógica. Pensar em uma pedagogia que se fundamente no princípio da participação, impõe inevitavelmente a dois movimentos: um direcionado ao posicionamento que traga de forma clara o tipo de participação que se toma como referência; outro, para uma contraposição com concepções impositivas, transmissivas, relacionadas ao modo de ensinar.

De acordo com Gambôa (2011), a escolha por uma pedagogia ou outra, define como será a relação da criança com o conhecimento (passivo/ativo), qual a forma como será construído (solitária/cooperativa) e principalmente, "qual a natureza do conhecimento - um conhecimento estático, fechado, transmitido versos um conhecimento em permanente construção, antidogmático, que valoriza o que recebe, mas desafia permanentemente as suas margens" (GAMBÔA, 2011, p. 50). Esse contraste representa $O$ cerne de pedagogias da transmissão e pedagogias da participação.

Fundada na lógica dos saberes, as pedagogias da transmissão fazem a veiculação desses saberes de forma descontextualizada e unidirecional, ocultam a realidade e as relações humanas, servem à dominação, por apresentarem-se de forma definitiva. Também compreendem o ser humano, em especial a criança, como um ser passivo, folha em branco a ser preenchida. A mente é vista como um espaço vazio a ser depositado algo.

\footnotetext{
Nessa concepção bancária da educação, o educador é quem educa, sabe, pensa, diz a palavra, disciplina, opta e prescreve a sua opção, atua, escolhe o conteúdo programático, [...] a educação orienta-se mais para a obediência que para a liberdade, mais para a submissão que para a participação (OLIVEIRA-FORMOSINHO, 2011a, p.17).
}

As pedagogias da participação, ao contrário, compreendem que todo e qualquer saber "parte exatamente do caráter histórico e da historicidade dos homens. Por isso mesmo é que os reconhece como seres que estão sendo, como seres inacabados, inconclusos, em e com uma realidade, que sendo histórica também, é igualmente inacabada" (FREIRE, 1983, p. 83). 
As pedagogias da transmissão representam integralmente os valores e lógica de mercado, manipulam a opinião pública no sentido de enaltecê-las como única garantia de sucesso e formação sólida, por transmitirem saberes julgados indispensáveis a esse sistema; ao mesmo tempo, desqualificam práticas pedagógicas fundadas na participação, associando-as a desordem, perda de tempo e ineficiência no ensinar (GAMBÔA, 2011). Romper com essa concepção do senso comum sobre pedagogias da participação requer ir além de pontuar aspectos que as caracterizam, "como nos ensina Paulo Freire, em pedagogia a ruptura não é um mero exercício de desocultação, mas sim um compromisso com a reconstrução e com a esperança" (OLIVEIRA-FORMOSINHO, 2007, p. 19).

\section{A DIMENSÃO LÚDICA E A CRIANÇA}

A concepção de criança, aqui entendida como sujeito que pertence a uma categoria geracional (SARMENTO, 2005) em um contexto histórico, social e cultural no qual é afetada, mas também o afeta através de suas produções e concepções sobre ludicidade.

A percepção sobre a relação das crianças com a ludicidade pode ser considerada recente ao relacioná-la com o percurso evolutivo humano. Somente a partir do século XVIII em decorrência das mudanças estruturais no campo da economia, das ciências e da tecnologia, a infância passou a ter maior evidência e a ludicidade como fator preponderante para o seu desenvolvimento. No universo infantil, a ludicidade se faz presente em várias atividades, mas especialmente na ação de brincar.

O brincar, a mais alta expressão da ludicidade, ainda que esteja presente em qualquer idade, ganha contornos expressivos para a criança, pois é especialmente por ele que há a forma mais significativa de aprendizagem, possibilitando o desenvolvimento pessoal, social e cultural, além de auxiliar para uma boa saúde mental, por fomentar a resiliência e a formação do autoconceito positivo (SANTOS, S., 2007). "No brincar, casam-se espontaneidade e criatividade com progressiva aceitação das regras sociais e morais. Em outras palavras, é brincando que a criança se humaniza" 
(OLIVEIRA, V., 2009a, p. 07), sendo, portanto, sua principal ferramenta para compreender-se como sujeito contextualizado no tempo e no espaço.

Essa construção ocorre especialmente através da cultura lúdica, com seus ritos (OLIVEIRA, V., 2009) ou com seus esquemas (BROUGÈRE, 2002), que criam as estruturas simbólicas necessárias para a passagem de regras mais imprecisas presentes nas brincadeiras simbólicas para regras mais precisas. Para Huizinga (2000) a regra garante o fluxo, à medida que, "cria ordem e é ordem. Introduz na confusão da vida e na imperfeição do mundo uma perfeição temporária e limitada, exige uma ordem suprema e absoluta: a menor desobediência a esta 'estraga o jogo'" (HUIZINGA, 2000, p. 13).

Da mesma forma, Oliveira, V., (2009), entende ser a seriedade e o compromisso ao contrato estabelecido, que introduzirá de forma significativa a criança ao mundo das regras sociais e morais.

\begin{abstract}
Quem brinca, de certa forma pisa em chão sagrado, já que acredita plenamente na realidade vivida e sentida, mergulhando fundo em suas águas, respeitando suas alianças. [...] O brincar da criança combina corpo e símbolo numa inserção gradual e progressiva no universo histórico-cultural, que contém regras sociais e morais que a ajudam a manter-se no eixo maior do respeito a si, ao outro e a liberdade (OLIVEIRA, V., 2009a, p. 26).
\end{abstract}

O brincar na infância fornece as bases mais sólidas para a construção da humanização do ser, permitindo que a criança possa sentir a tristeza da perda ou da dor, compreendida como sensação que pode ser superada e Ihe ajudarão a se tornar mais humana, especialmente quando há empatia nas relações. Nessa perspectiva se tem a formação docente que é essencial para possibilitar a ludicidade para a criança.

Neste contexto, a compreensão da ludicidade como um princípio formativo na ação docente, imprescindível durante a formação deve ser considerado algo recente. A ideia que perdurou durante muito tempo nos cursos de formação inicial pautava-se, sobretudo, na lógica tecnicista. A formação lúdica, no entendimento de Santos e Cruz (2007), é a base de um novo pilar para a formação profissional docente, porque nela se assenta a formação pessoal, humana, a qual comporta "pressupostos que valorizam a 
criatividade, o cultivo da sensibilidade, a busca da afetividade, a nutrição da alma" (SANTOS e CRUZ, 2007, p. 14).

Lombardi (2010) refere-se à formação lúdica aproximando-a da formação corporal, pontuando que sua inexistência deixa uma grande lacuna na formação e reflete em ações docentes que tendem a reprimir expressões e movimentos relacionados à corporeidade na infância.

A dimensão lúdica, em práticas pedagógicas, exige refinamento de olhar, trato e envolvimento, aspectos construídos e conquistados somente com muita dedicação e estudo. Vale salientar, ainda, que o saber lúdico não é inato, se sustenta especialmente em situações experienciais advindas da memória biográfica construída durante a infância. Também se apoia em experiências formativas de ordem prática, bem como em estudos e pesquisas que contemplam aportes teóricos e conceituais sobre diferentes aspectos da ludicidade e sua relação com o campo educacional.

A prática pedagógica pautada na dimensão lúdica é uma demonstração da inquietude com práticas que adestram o saber e o querer, ao distanciar ou até mesmo impedir um envolvimento com o objeto do conhecimento. A construção do saber lúdico, incorporado ao processo de formação deve ter aversão por uma visão mistificadora da ludicidade que a apresenta de forma romântica e descontextualizada, dissociando-a dos diversos campos de conhecimento e reduzindo-a a atividades estéreis. $O$ saber lúdico deve provocar a necessidade constantemente de "estudar apaixonadamente o brincar, com seriedade" (FORTUNA, 2018, p. 25), pois um trabalho que envolve sensibilidade, emoção e interações, o preparo, seja ele de que ordem for, torna-se indispensável ser feito com inteireza, com plenitude, com paixão.

\section{PROCEDIMENTOS METODOLÓGICOS: O LUGAR AONDE SE QUER CHEGAR}

As escolhas metodológicas apresentam pistas importantes sobre onde e como se queria chegar com a pesquisa, pois a maneira como se realiza, lembra Minayo (2009b), "revela as preocupações científicas dos 
pesquisadores que seleciona tanto os fatos a serem observados, coletados e compreendidos como o modo como vai recolhê-los" (MINAYO, 2009b, p. 63).

Por ter como objeto de pesquisa a dimensão lúdica na Educação Infantil, a abordagem qualitativa, ancorada no método Estudo de Caso, tornou-se a opção mais coerente. Dentre os fatores que fortaleceram a escolha deste método, encontram-se as pontuações de Yin $(2015$, p. 04), por considerar que "um estudo de caso permite que os investigadores foquem um 'caso' e retenham uma perspectiva holística e do mundo real".

Com este entendimento, sua realização inevitavelmente, ocorreu em um contexto escolar, mais especificamente em uma escola de Educação Infantil localizada no Município de Macapá, Estado do Amapá, tendo como sujeitos da relação de pesquisa um grupo de professoras e suas respectivas crianças do contexto amazônico. Essa proximidade com a escola, além de possibilitar e interagir com os sujeitos e a realidade em que se encontravam, favoreceu a coleta de dados, realizada através de: entrevista semiestruturada e o grupo focal com os professores; rodas de conversa com as crianças e observação participante nos contextos de cada professora com seus alunos.

Para o processo de análise dos dados, tomou-se como referência os princípios da Hermenêutica-Dialética, apoiada nos procedimentos metodológicos sugeridos por Minayo (2002; 2006). A opção por esta base teórica levou em consideração o fundamento de duas correntes: compreensão e crítica. De acordo com Minayo (2002, p. 101) "uma análise hermenêutica-dialética busca apreender a prática social empírica dos indivíduos em sociedade em seu movimento contraditório".

Convém destacar que o processo de análise, assim como todo o percurso da pesquisa, considerou os princípios éticos como ponto balizador. Além dos procedimentos formais e burocráticos, como submissão ao Comitê de Ética em Pesquisa (CEP), todo o caminhar, especialmente quando do contato com os participantes, foi condicionado ao interesse espontâneo em participar, sem nenhum tipo de coação, baseado em uma relação de 
cordialidade, em que o respeito às falas e posicionamentos manteve-se sempre presente.

\section{O LUGAR DA DIMENSÃO LÚDICA NA EDUCAÇÃO INFANTIL: CONSENSOS E CONTRADIÇÕES}

A operacionalização do momento de análise, sustentada pela Hermenêutica-dialética, permitiu "que provisoriamente e apenas para fins analíticos se toma[sse] o material de representação social como um conjunto separado, a ser tecnicamente trabalhado" (MINAYO, 2006, p. 234). A leitura compreensiva do material permitiu a ordenação e classificação dos dados ao favorecer "de um lado, ter uma visão de conjunto e, de outro, apreender as particularidades do material" (GOMES, 2009, p. 100), permitindo organizá-los considerando as perguntas norteadoras da pesquisa e em seguida "reagrupadas em torno de categorias centrais, concatenando-se numa lógica unificadora" (MINAYO, 2006, p. 236).

O princípio de separação do material apoiado nas categorias centrais, representadas nesta pesquisa sob o formato de temáticas, permitiu um aprofundamento dos assuntos mais relevantes ao "fazer uma articulação entre os objetivos do estudo, a base teórica adotada e os dados empíricos" (GOMES, 2009, p. 101), e deixando transparecer os pontos julgados pertinentes na opinião da pesquisadora. A pesquisa discute a categoria que representa o cerne da investigação, que se refere a dimensão lúdica e práticas pedagógicas: "Eu estudo para ser inteligente e brinco pra ser feliz!".

A análise desta categoria busca contemplar as seguintes perguntas norteadoras: Em que aspectos a dimensão lúdica pode ser considerada importante para a Educação Infantil? Como na Educação Infantil a ludicidade pode ser instrumento de pedagogização da infância? Quanto à burocratização na docência impõe ao professor separar ludicidade de aprendizagem? Qual a percepção das crianças e das professoras em relação à aprendizagem e as práticas lúdicas? Quais tipos de relações às professoras estabelecem entre participação da criança em seu processo de conhecimento e a ludicidade? 
Durante a realização da entrevista, ao ser questionada sobre o quanto a ludicidade poderia contribuir ou prejudicar no ambiente escolar, a Professora Pl afirmou: "Eu não vejo assim, nada que vá prejudicar. Eu acho que só vem pra contribuir". Para a Professora P2, a ludicidade no ambiente escolar deve ser sempre auxiliada por conteúdos e metodologia que tornem a aula prazerosa e que permitam o aprendizado. A professora afirma: "Na Educação Infantil a ludicidade é o fator principal. Porque é através do lúdico, que de maneira prazerosa é que as aprendizagens e o conhecimento acontecem. [...]" (Professora P2 - Entrevista 2019). Wajskop (2012) identifica em práticas onde a brincadeira aparece em atividade controlada apenas pelo professor, como forma de seduzir as crianças e despistá-la dos objetivos escolares pretendidos com a atividade. Convém ressaltar que a autora, ao fazer tais ponderações referia-se às práticas verificadas durante sua pesquisa, que em nada continham a essência da dimensão lúdica.

Sobre a frequência que a ludicidade deve se fazer presente na Educação Infantil, no sentido ainda voltado para a sua importância, a Professora P3 foi enfática ao afirmar: "Deve se fazer presente sempre. Sempre presente! Sempre, sempre, sempre! Eu não vejo ela como ausente". (Professora P3 - Entrevista 2019). Já no Grupo Focal a Professora P3, inicialmente reforçou esta colocação, quando se posicionou a favor da brincadeira: "Elas até aprendem mais. Eu discordo que atrapalha a aprendizagem, ela não atrapalha, ela só enriquece a aprendizagem" (Professora P3 - Grupo Focal 2019). Como também pontuou que esta forma de desenvolver a prática não representa um trabalho excessivo, ao contrário, como pode ser compreendido em seu depoimento: "É até prazeroso. A gente sai de sala de aula um pouco e aprende junto com eles. Eu discordo, não é um trabalho excessivo é um trabalho prazeroso!" (Professora P3 - Grupo Focal). No entanto, no decorrer das discussões voltadas para as orientações recebidas por instituições e setores externos à escola, que prestaram orientações voltadas às práticas pedagógicas e ao 
atendimento do currículo pela Educação Infantil, externou outro pensamento:

Mas eles esquecem um ponto muito importante, eles querem só que a gente faça, é... fora... quase nada de xérox, mas a gente tem caderneta, e nossos conteúdos? Como lançar nas cadernetas? Todo tempo só brincadeiras, brincadeiras, brincadeiras, fora de sala de aula? A gente também tem que ter é... desenvolver a coordenação, linguagem oral e escrita da criança (Professora P3 - Grupo Focal, 2019).

Essa contradição, atribuída à presença da ludicidade que ressoou no posicionamento das demais professoras participantes, se fez mais enfática pelo fato que ao final da semana, anterior a realização da sessão do Grupo Focal, ter ocorrido uma formação voltada para a implantação da Base Nacional Comum Curricular - BNCC e do Referencial Curricular Amapaense RCA e terem, os coordenadores do evento, segundo as professoras, rechaçado o uso contínuo de atividades convencionalmente chamadas de xérox, ao mesmo tempo, deram ênfase na necessidade de contemplarem em suas ações as orientações didáticas contidas no documento. É neste sentido que veio o esclarecimento pelas professoras colaboradoras, sobre o uso desse tipo de material e a participação ativa das crianças:

A Secretaria [SEMED] veio justamente reclamar por conta da quantidade de xérox que nós temos trabalhado com as crianças. Ela não "tá" vendo, segundo eles, questão da construção da criança com relação a essas atividades. Aí eles cobram que a gente trabalhe com material concreto. Mas, a atividade em si, se a gente for levar só pela questão da xérox, talvez a gente peque por isso, por essa questão, mas a gente não utiliza a xérox simplesmente por nada, a gente utiliza recorte e colagem, a gente utiliza sementes, a gente utiliza aparas de lápis, tinta guache... Com algodão. Atividades que levem materiais, mais assim, manuseáveis para que a criança aprenda essa questão de coordenação viso-motora. Então, de alguma forma a gente "tá" trabalhando algo na criança. Então ela não é $100 \%$, digamos... pedagogicamente correta, digamos assim, mas a criança também tem lá parte ali, ela também constrói (Professora P2 - Grupo Focal 2019).

Wajskop (2012, p. 94) lembra que folhas mimeografadas, hoje impressas ou fotocopiadas, tem sua origem em materiais decrolyanos, cuja "descontextualização ante a época atual não trazem desafios às crianças, que as preenchem com gestos mecânicos e involuntários". Nesta pesquisa 
não se tem a pretensão de julgar a validade desse tipo de atividade, apenas pontuar sua presença no cotidiano nas salas de aula da EMEI campo de pesquisa, visto que a atividade impressa, em si, pode ser tanto desencadeadora de inúmeras intervenções e descobertas pelas crianças, como podem servir apenas para treinamento de requisitos considerados básicos à alfabetização. Neste sentido, sua finalidade e encaminhamentos de como será explorada, estará condicionada ao tipo de mediações e metodologias utilizadas pela professora e a frequência em que são propostas.

Com relação ao processo de formação voltado à implementação da BNCC/RCA, Carvalho, Silva e Lopes (2019) consideram que essas estratégias discursivas visam a pedagogização da docência, "por meio das quais se busca decodificar, traduzir e ensinar para os professores de um modo acentuadamente prescritivo e 'didático' as orientações" contidas nos manuais (CARVALHO; SILVA; LOPES, 2019, p. 01). Possivelmente foi o que deixou as professoras apresentarem um diálogo um pouco tenso durante 0 Grupo Focal, no momento em que houve as colocações sobre as orientações recebidas durante a formação. As discordâncias, entretanto, não eram entre si, mas frente à situação posta pela equipe que coordenava o evento. Para Bujes (2001), estas ações se configuram em vigilância que se dissemina por todo o corpo institucional. Ainda segundo a autora, o controle constante ocorre de forma que "o indivíduo é visto sem poder ver, o poder que vigia utiliza apenas o instrumento do olhar e não da coação" (BUJES, 2001, p. 118).

Essa abrangência da vigilância, além dos setores institucionais internos e externos, mobiliza os pais. As professoras sentem-se na obrigação de apresentar resultados por meio de registros que comprovem a produtividade de sua ação, especialmente quando voltados para a aquisição da leitura e escrita, pois de acordo com as professoras, quando a criança da Educação Infantil entra no Ensino Fundamental, vai ser cobrado que tenha certas habilidades, "só que é colocado pra gente fazer certas coisas e os pais 
pedem outras e a gente fica nesse impasse aqui" (Professora P2 - Grupo Focal 2019).

O pai quer que saia lendo e escrevendo. Ele faz, briga e cobra porque você não fez nada. E tem o patrão lá de cima que diz que não é assim, a Educação Infantil não é pra alfabetizar, a Educação Infantil é pra isso... e a gente fica no meio disso aí sem saber o que fazer (Professora P4 - Grupo Focal 2019).

Carneiro (2010) pontua que há uma grande preocupação entre os professores de cumprir o currículo, mesmo que esteja desvinculado dos interesses e necessidades infantis, o que leva "pais e professores questionarem-se quais as vantagens do brincar do ponto de vista da aprendizagem dos conteúdos esperados, especialmente, porque seus conteúdos não podem ser quantificados" (CARNEIRO, 2010, p. 30). Lira (2008) acredita que a ênfase na pedagogização das práticas realizadas na Educação Infantil, tem revelado "rituais que priorizam a escrita e o cálculo, acompanhados pelos tradicionais procedimentos pedagógicos, muitas vezes deteriorando inclusive as experiências com o brincar, tão importantes para a infância" (LIRA, 2008, p. 320). O lugar da dimensão lúdica passa então a ser claramente questionado pelas professoras participantes, como pode ser constatado no diálogo abaixo:

Daqui ele vai para o primeiro ano. No primeiro ano vai ser totalmente diferente, a gente é orientada que a Educação Infantil deve fazer muita prática e lá [Ensino Fundamental] eles vão "pro" caderno, vão copiar. Essa criança vai chegar lá e aí o que vai acontecer? "Ah, ele é lá da EMEI. Foi lá na EMEI que ele estudou. Então, lá só é brincadeira!". Só que a gente é orientada a trabalhar assim, vem lá de cima e a gente tá aqui só... obedecendo (Professora P4 - Grupo Focal, 2019).

No depoimento das professoras, as evidências de preocupações ligadas à entrada das crianças nas escolas do Ensino Fundamental, fortalecem a ideia de antecipação e preparação para $\circ 1^{\circ}$ ano como forma de evitar o fracasso na etapa seguinte. Wajskop (2012) tece comentários a esse respeito:

A concepção compensatória de ensino e aprendizagem marca o ideário da professora que, no cotidiano escolar, prioriza as atividades

Revista Exitus, Santarém/PA, Vol. 12, p. 01-25, e022004, 2024. 
dirigidas e gráficas como conteúdo do seu trabalho. Essas atividades são, geralmente, exercícios gráficos e motores, de treino de habilidades linguísticas ou de repetição de regras e comportamentos que definem hábitos e atitudes (WAJSKOP, 2012, p. 84).

Tais posturas são resquícios da forma como a Educação Infantil foi implantada, configurando-se uma "pré-escola" no sentido literário da palavra. Os impasses apresentados pelas professoras geram práticas inadequadas, não só porque não atendem aos seus próprios anseios, mas porque acabam "desrespeitando a aquisição de experiências com sentido pela criança e desvalorizando a representação simbólica e o brincar" (LIRA, 2008, p. 324).

A pedagogização do professor que opera o governamento docente (BUJES, 2001) através de orientações teórica, posições normativas e "vocabulário pedagógico comum, [...] transforma não apenas o que a professora de Educação Infantil faz ou sabe, mas a sua própria maneira de ser" (CARVALHO; SILVA; LOPES, 2019, P. 03), além de levar a pedagogização da infância. "Muitas vezes damos lugar em nossas salas de aula apenas para o controle, a privação, a punição, a vigilância, o governo de si e do outro" (DORNELLES, 2001, p. 107). Assim, a dimensão lúdica só encontra lugar quando se apresenta no invólucro da lógica escolar, sustentada por objetivos pedagógicos.

A categoria ludicidade, quando compreendida apenas como recurso pedagógico, separada das relações e atuações humanas em suas diversas dimensões fica subjugada aos propósitos de outrem, não sendo vista como "uma parte natural de nossa vida e que tem valor tanto para as crianças quanto para os adultos" (MOYLES, 2002). No entanto, entendida como processo, passa a ser percebida dentro da ação e não mais como uma forma de atividade pontual ou necessária apenas para a introdução de temáticas, cujos fins são exclusivamente escolares. Essa não compreensão implica na organização das atividades que serão desenvolvidas em sala de aula, no sentido de que o lugar ocupado e permitido para a dimensão lúdica passa a ser uma decisão exclusiva do adulto responsável pela 
condução da aula, havendo, implícita e explicitamente, o momento "lúdico" e o momento "sério".

Todo momento ela pode estar inclusa na Educação Infantil, sendo que nós temos o momento da parte teórica que nós temos todo um planejamento, com os conteúdos, mas você "puxando" ela para "puxar" os conteúdos, ela já vai ser envolvida. Mas tem momento que você tem que deixar ela um pouquinho de lado e trabalhar só a parte teórica (Professora P5 - Entrevista 2019).

Têm momentos que você não... "Agora é o momento da atividade, vamos fazer!". Então nesse momento, geralmente a gente não utiliza. Eu pelo menos não. Tem também aquele momento que a criança tá demais sapeca, e o professor precisa ter um pouco de autonomia e dizer: "Não, agora, não! Nós vamos ter nosso momento do brinquedo, agora não! É o nosso momento da atividade" (Professora P2 - Entrevista 2019).

A divisão da aula em momentos constrói uma rotina que pode ser vista como importante aliada na estruturação do tempo subjetivo pelas crianças, como também pode servir para padronizar tempo e espaço de modo a submetê-las às ações disciplinares da instituição escolar. Fato que, dentro do contexto escolar existe um tempo delimitado de horas e que, portanto, necessita de um planejamento para otimizar suas ações, e a rotina pode auxiliar neste ponto. Barbosa (2006, p. 37) compreende que as rotinas facilitam a aprendizagem de "certas ações que, com o decorrer do tempo, tornam-se automatizadas, pois é necessário ter modos de organizar a vida". Mas, no caso do espaço escolar, a estruturação das rotinas, quase sempre esteve associada a uma "estratégia pedagógica necessária para a formação de sujeitos adaptados aos tempos modernos" (BARBOSA, 2006, p. 89), onde, além de rituais, padronização de comportamentos e controle disciplinar, há uma clássica divisão entre "hora de brincar" e "hora séria da atividade", que de tal forma se instalam no inconsciente coletivo, que levam professoras, pais e as próprias crianças, a não validarem como "aula" os momentos que fogem dela. O diálogo abaixo (Grupo Focal 2019) reflete o quanto a incorporação da dimensão lúdica, que desvirtua da rotina padrão, é mal compreendida não só pelos pais, mas também pelas crianças: 
- Sexta-feira o meu aluno... A gente passou a manhã inteira fazendo atividades diversas, mas assim nada escrito, nada. Só brincando mesmo. Aí ele: "Professora, a gente nem teve aula hoje!". E eu falei: "Como que a gente não teve aula? Se você brincou ali, se você fez aquela atividade ali, se a gente criou ali?". "Não professora, mas eu não fiz nada no meu livro, eu não fiz nada no meu caderno!". Aí eu falei: "Tá, outro dia a gente faz!" (Professora P4).

- Porque os pais cobram (Professora P2).

- Eles cobram, eles querem ver (Professora P5).

- Tem pai que pensa que quando a criança vem pra escola e só tá brincando ele não tá aprendendo (Professora P3).

A tendência dos pais em não valorizar esses momentos, pode estar relacionada à correria do cotidiano ou a excessiva preocupação com o futuro das crianças, associando-o ao mercado de trabalho. Moyles (2002) lembra que um dos principais argumentos dos pais repousa no fato que mais cedo ou mais tarde as crianças terão que enfrentar as duras rotinas da vida adulta, então quanto mais cedo se acostumarem, melhor. Santos (2010) tece uma reflexão sobre a questão:

Certo é que vivemos um momento de grandes contradições porque ao mesmo tempo em que se valoriza o brincar, enquanto atividade capaz de favorecer o desenvolvimento dos pequenos, percebe-se a sua desvalorização por considerá-lo uma mera perda de tempo (SANTOS, 2010, p. 112).

Posicionamentos contraditórios dos adultos são incorporados à fala das crianças, como na narrativa anterior da Professora P5, mas também constatada durante uma das rodas de conversa apresentada a seguir:

Criança 1- Se a gente vier só pra escola pra gente brincar, a gente não aprenderia nada, não poderia ter um bom trabalho.

Pesquisadora - Vocês ouviram o que a Kelly "tá" falando?

Criança 1 - E não ia ganhar dinheiro.

Pesquisadora - Se a gente não aprender as coisas a gente não ganha dinheiro?

Crianças - Não!

Criança 1 - Se a gente não tiver como trabalhar, a gente não vai ganhar dinheiro (Roda de conversa 2 - 17/08/2019).

Kato et al. (2010) pontuam que o tempo de brincar tem sido reduzido em consequência do fenômeno "adultização" precoce. "Observa-se com preocupação um afã na aceleração desse processo maturacional, no 
sentido de um despertar precoce para o desenvolvimento funcional com vistas a uma pretensa preparação para o mercado de trabalho" (KATO et al., 2010, p. 49). Mas se entre muitos adultos o discurso de valorização das atividades lúdicas se esvazia na prática, com as crianças acontece justamente $\mathrm{o}$ inverso. Ainda que "as crianças sempre querem agradar os adultos com quem mantêm um contato regular e fazer o que eles parecem desejar" (MOYLES, 2002, p. 98), quando expostas a situações que Ihes trazem prazer, se entregam plenamente, ludicamente. Porque a essência de ser criança é cristalizada no presente, no agora e "o brincar não é um escape da vida: é uma parte integral da vida" (MOYLES, 2002, p. 175). O que ficou evidente em todas as rodas de conversa, exemplificadas por uma, a seguir:

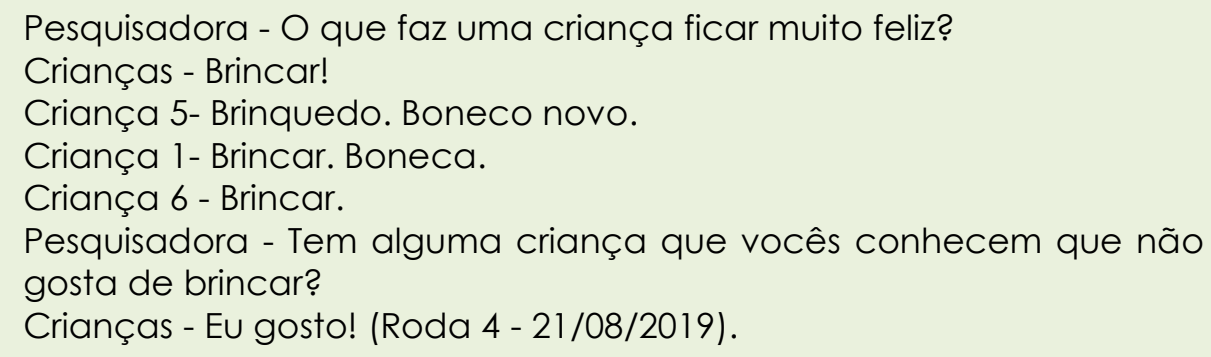

Na realização das rodas de conversa, quando diante de imagens de crianças com fisionomias que sugeriam tristeza, raiva e medo, as crianças divagavam sobre as hipóteses dos motivos que as levaram a reagirem daquela forma. No entanto, quando diante de uma imagem de uma criança com um largo sorriso, foram unanimes em dizer que era porque estava brincando. Foi neste momento que faziam um paralelo entre o brincar e o aprender:

Pesquisadora - Pra quê a gente estuda?

Criança 1- Pra ficar inteligente!

Pesquisadora - E pra quê que a gente brinca?

Criança 1- Pra ficar feliz.

Pesquisadora - A gente fica inteligente brincando?

Crianças - Não!

Pesquisadora - E quem estuda não fica feliz?

Criança 1- Fica burro! Quem não estuda fica burro!

Pesquisadora - Mas será que todo mundo que não estudou é burro?

Criança 1 - Quase todo mundo (Roda 3 - 21/08/2019). 
Esses são os primeiros indícios de como as crianças percebem as atividades propostas pelas professoras. Entendem que somente através do estudo podem aprender algo e até admitem que possam sentir-se felizes quando estudam, mas não é esse o objetivo de estarem na escola. Contudo, o inverso, aprender algo brincando, se divertindo, não thes é possível. A forte presença da afirmativa usada pelas crianças, atribuindo os adjetivos inteligente e feliz, às ações de estudar e brincar, consecutivamente, instigou a curiosidade de como as professoras iriam perceber este posicionamento vindo de suas crianças. Neste sentido, a frase "Eu estudo para ser inteligente e brinco pra ser feliz!" foi construída e apresentada para finalizar a última sessão do Grupo Focal, tendo como pontuações da narrativa que segue:

\begin{abstract}
"A gente estuda pra ficar inteligente...". Mas o que seria ficar inteligente pra ele? E "brinca pra ficar feliz"... Estudar e brincar não pode "tá" relacionado. Então quando ele fala isso ele "tá" muito maduro nesse pensamento, esse é um pensamento um pouco desforme do que a gente aprende o que seja estudar e brincar. Porque pra gente essa compreensão... fora que as coisas na Educação Infantil andam juntas. [...] Quem é que anda dizendo isso pra essa criança? Como é que ele formou esse pensamento de ficar inteligente, de estudar pra ser inteligente, e brincar, somente pra ser feliz? Será que a gente não consegue ser feliz estudando e brincando ao mesmo tempo, unindo as duas coisas? Então é algo assim que a gente precisa trabalhar essa criança. "Pra" ele poder reformular esses conceitos, do que seria estudar, brincar, pra que serve a educação, a escola (Professora P4 - Grupo focal 2019).
\end{abstract}

Alguns detalhes, presentes na rotina das salas de aula, podem ter induzido as crianças a separarem o estudar do brincar. Os momentos que foram citados pelas crianças onde o brincar ganhava espaço e é permitido, sem que houvesse prejuízo ao aprender, foram: o parquinho e o "Dia do Brinquedo", mas também mencionaram que brincam com massinha e brinquedos de montar. Os momentos do brincar, sempre estavam associados aos momentos do não estudar, como: enquanto a aula não começa; quando termina a atividade; em local específico e em dia marcado. Moyles (2002, p. 34) compreende que as crianças chegam à escola com experiências e expectativas diferentes sobre o brincar e "logo percebem 
que certos comportamentos de brincar são inadequados no contexto escolar" e dependendo das relações que são estabelecidas podem, ao serem "indagadas sobre o que estavam aprendendo com essa atividade, responder que não deveriam aprender nada [...] porque a professora dissera que eles estavam lá 'só pra brincar'" (MOYLES, 2002, p. 35), e isso nada se relaciona com o estudar.

\section{CONSIDERAÇÕES FINAIS}

Resta pontuar que "mais importante que analisar as práticas é perceber as relações que nelas se estabelecem e, consequentemente, seus efeitos" (LIRA, 2008, p. 320). No caso do lugar da dimensão lúdica na Educação Infantil, o quanto os consensos representam verdadeiramente valorização e o quanto as contradições imprimem conflitos internos ou reflexos de fatores externos.

As cirandas estão sendo esquecidas e com elas a harmônica combinação entre "os limites com a liberdade, a criatividade, o divertimento, a curiosidade, a fantasia, a aprendizagem e a alegria" (SANTOS, 2010, p. 112) têm sido esquecidos. A criança, apesar de ter conquistado a condição de sujeito social, histórico e cultural, contraditoriamente, vem perdendo o direito ao espaço e ao tempo para vivenciar sua infância de forma singular. Restam-lhes apenas as gangorras, que nos seus movimentos alternados de subida e descida, permitem por alguns instantes, que a criança deixe de ser aluno, para ser apenas criança.

\section{REFERÊNCIAS}

AMORIM, L. O. Cartas sobre Educação Infantil de Johann Heinrich Pestalozzi: imagens de mãe na correspondência de educadores. 128 f. Dissertação (Mestrado) - Universidade Metodista de Piracicaba, Pós-Graduação em Educação, Piracicaba, 2018.

BARBOSA, M. C. S. Por amor e por força: rotinas na educação infantil. Porto Alegre: Artemed, 2006. 
BRASIL. Lei de Diretrizes e Bases da Educação Nacional: lei n 9.394, de 20 de dezembro de 1996, que estabelece as diretrizes e bases da educação nacional. Brasília: MEC, 1996.

BROUÈRE, G. A criança e a cultura lúdica. In. KISCHIMOTO, T. M. O brincar e suas teorias. São Paulo: Pioneira Thomson Learning, 2002.

BROUÈRE, G. Uma teoria de aprendizagem adaptada: a aprendizagem como participação. In: BROUĖRE, G.; ULMANN, A. (Orgs.). Aprender pela vida cotidiana. Trad. Antonio de Paula Danesi. Campinas: Autores Associados, 2012.

BUJES, M. I. E. Infância e maquinarias. 2001. Tese (Doutorado em Educação) Programa de Pós-Graduação em Educação, Universidade Federal do Rio Grande do Sul, Porto Alegre, 2001.

CARNEIRO, M. Â. B. Memória e patrimônio: a cultura da infância e do brincar. In: CARNEIRO, M. Â. B. (org). Cócegas, carambolas e esconderijos:

construindo culturas e criando vínculos. São Paula: Articulação Universidade Escola, 2010.

CARVALHO, R. S.; SILVA, M. O.; LOPES, A. O. A pedagogização da docência. Anais eletrônico $8^{\circ}$ Seminário Brasileiro de Estudos Culturais e EducaçãoSBECE $/ 5^{\circ}$ Seminário Internacional de Estudos Culturais e Educação - SIECE. Ser/Estar emergentes e/na educação. 25 a 27 de junho de 2019. Disponível em: <https://www.2019.sbece.com.br/site/anais2? AREA=11>. Acesso em: 10 dez. 2019.

COMENIUS, I. A. Didática Magna. Introdução, tradução e notas de Joaquim Ferreira Gomes. Fundação Calouste Gulbenkian. 2001. Disponível em: <http://www.ebooksbrasil.org/adobeebook/didaticamagna.pdf >. Acesso em: 14 dez. 2018.

DORNELLES, L. V. Na escola infantil todo mundo brinca se você brinca. In: CRAIDY, C. M.; KAERCHER, G. E. P. Silva. (Org). Educação Infantil: pra que te quero? Porto Alegre: Artmed, 2001.

FORTUNA, T. R. Formação lúdica docente: como os professores que brincam se tornam o que são? In: D'AVILA, C; FORTUNA, T. R. (org.). Ludicidade, cultura lúdica e formação. Curitiba: CRV, 2018.

FREIRE, P. Pedagogia do oprimido. 13 ed. Rio de Janeiro: Paz e Terra, 1983.

GAMBÔA, R. Pedagogia-em-Participação: Trabalho de Projeto. In: OLIVEIRAFORMOSINHO, J.; GAMBÔA. R. (org.). O Trabalho de Projeto na Pedagogiaem-Participação. Porto Editora: Portugal, 2011.

GASPARIN, J. L. As ideias de Pestalozzi no Brasil. Recife: Massangana, 2010. 
GOMES, R. Análise e interpretação de dados de pesquisa qualitativa. In: MINAYO, M. C. S. (org.). Pesquisa social: teoria, método e criatividade. 28 ed. Petrópolis: Rio de Janeiro: Vozes, 2009.

HUIZINGA, J. Homo Ludens. 4 ed. Tradução João Paulo Monteiro. São Paulo: Editora Perspectiva S.A., 2000.

KATO, R. A. F.; KRACHER, C. K.; KOLESNIKOVASE, I. H.; SILVA, P. S. Aspectos psicológicos acerca do brincar. In: CARNEIRO, M. Â. B. (org.). Cócegas, carambolas e esconderijos: construindo culturas e criando vínculos. São Paula: Articulação Universidade Escola, 2010.

KISHIMOTO, T. M. Brinquedos e brincadeiras: usos e significações dentro de contextos culturais. In: SANTOS, S. M. P. (org.). Brinquedoteca: o lúdico em diferentes contextos. Petrópolis, RJ: Vozes, 1997.

KISHIMOTO, T. M. Froebel e a concepção de jogo infantil. In: KISHIMOTO, T. M. (org.). O brincar e suas teorias. São Paulo: Pioneira Thomson Learnig, 2002.

LIRA, A.C.M. Pedagogização na infância: refletindo sobre poder e regulação. Inter-Ação: Rev. Fac. Educ. UFG, 33 (2): 317-341, jul./dez. 2008.

LOMBARDI, L. M. S. S. Jogos teatrais, expressão corporal e docência. In:

CARNEIRO, M. Â. B. (org). Cócegas, carambolas e esconderijos: construindo

culturas e criando vínculos. São Paulo: Articulação Universidade Escola, 2010.

LOPES, M. C. O. Aprender e ensinar a brincar. In: D'AVILA, C.; FORTUNA, T. R. (org.). Ludicidade, cultura lúdica e formação. Curitiba: CRV, 2018.

LUCKESI, C. C. Brincadeiras, jogos e ludicidade. In: D'ÁDIVA, C. FORTUNA, T. (org.). Ludicidade, cultura lúdica e formação de professores. Curitiba: CVR, 2018.

MINAYO, M. C. S. Hermenêutica-Dialética como caminho do pensamento social. In: MINAYO, M. C. S.; DESLANDES, S. F. (org). Caminhos do pensamento: epistemologia e método. Rio de Janeiro: Editora Fiocruz, 2002.

MINAYO, M. C. S. O desafio do conhecimento: pesquisa qualitativa em saúde. São Paulo: Hucitec, 2006.

MINAYO, M. C. S. O desafio da pesquisa Social. In: MINAYO, M. C. S. (org.). Pesquisa Social: teoria, método e criatividade. Petrópolis, Rio de Janeiro: Vozes, 2009a.

MOYLES, J. R. Só brincar? O papel do brincar na educação infantil. Tradução Maria Adriana Veríssimo Veronese. Porto Alegre: Artmed, 2002.

OLIVEIRA, Z. M. R. Educação Infantil: fundamentos e métodos. São Paulo: Cortez, 2011. 
OLIVEIRA, V. B. O brincar e a criança do nascimento aos seis anos. In: OLIVEIRA, V. B. de (org.). O brincar e a criança do nascimento aos seis anos. 8 ed. Petrópolis: Vozes, 2009a.

OLIVEIRA, V. B. O brincar e o ingresso no tempo histórico e cultural. In: OLIVEIRA, V. B. de (org.). O brincar e a criança do nascimento aos seis anos. 8 ed. Petrópolis: Vozes, 2009b.

OLIVEIRA-FORMOSINHO, J. Pedagogia(s) da infância: reconstruindo uma práxis de participação. In: OLIVEIRA-FORMOSINHO, J.; KISHIMOTO, T. M.; PINAZZA, M. A. (org.). Pedagogia(s) da Infância: Dialogando com o passado, construindo o futuro. Porto Alegre: Artmed, 2007.

OLIVEIRA-FORMOSINHO, J. A perspectiva da associação criança: A Pedagogia-em-Participação. In: OLIVEIRA-FORMOSINHO, J. (org.). Modelos curriculares para a educação de infância: Construindo uma práxis de participação. 4 ed. Porto Editora: Portugal, 2011 a.

PONCE, A. Educação e luta de classes. 20 ed. Tradução José Severo de Camargo Perreira. São Paulo: Cortez, 2003.

SANTOS, S. M. P. Atividades lúdicas. In: SANTOS, S. M.P. (org.). O lúdico na formação do educador. 2 ed. Petrópolis: Vozes, 2007.

SANTOS, S. M. P.; CRUZ, D. R. M. O lúdico na formação do educador. In: SANTOS, S.M. P. (org.). O lúdico na formação do educador. 2 ed. Petrópolis: Vozes, 2007.

SANTOS, M. W. Multiculturalismo e prática cotidiana: desafios de educar na diversidade. In: CARNEIRO, M. Â. B. (org). Cócegas, carambolas e esconderijos: construindo culturas e criando vínculos. São Paulo: Articulação Universidade Escola, 2010.

SARMENTO, M. J. Gerações e alteridade: interrogações a partir da sociologia da infância. Educ. Soc., Campinas, vol. 26, n. 91, p. 361-378, Maio/Ago. 2005. Disponível em: <http://www.scielo.br/pdf/es/v26n91/a03v2691.pdf>. Acesso em: 05 jan. 2020.

WAJSKOP, G. Brincar na educação infantil: uma história que se repete. $9^{a}$ ed. São Paulo: Cortez, 2012.

YIN, R. K. Estudo de caso: Planejamento e métodos. $5^{a}$ ed. Porto Alegre: Bookman, 2005.

Recebido em: 12 de setembro de 2021. Aprovado em: 21 de dezembro de 2021. Publicado em: 07 de janeiro de 2022. 